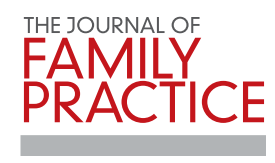

EDITOR-IN-CHIEF

JOHN HICKNER, MD, MSC

Professor Emeritus

Michigan State University

College of Human Medicine

ASSOCIATE EDITOR

RICHARD P. USATINE, MD

University of Texas Health

at San Antonio (Photo Rounds)

ASSISTANT EDITORS

DOUG CAMPOS-OUTCALT, MD, MPA

University of Arizona

RICK GUTHMANN, MD, MPH

Advocate Illinois Masonic Family Medicine

Residency, Chicago

ROBERT B. KELLY, MD, MS

Fairview Hospital, a Cleveland Clinic hospital

GARY KELSBERG, MD, FAAFP

University of Washington, Renton

COREY LYON, DO

University of Colorado, Denver

KATE ROWLAND, MD, MS

Rush-Copley Medical Center, Chicago

E. CHRIS VINCENT, MD

University of Washington, Seattle

EDITORIAL BOARD

FREDERICK CHEN, MD, MPH

University of Washington, Seattle

JEFFREY T. KIRCHNER, DO, FAAFP, AAHIVS

Lancaster General Hospital, PA

TRACY MAHVAN, PHARMD

University of Wyoming, Larami

MICHAEL MENDOZA, MD, MPH, MS, FAAFP University of Rochester, NY

FRED MISER, MD, MA

The Ohio State University, Columbus

KEVIN PETERSON, MD, MPH

University of Minnesota, St. Paul

MICHAEL RADDOCK, MD

The MetroHealth System, Cleveland, $\mathrm{OH}$

MICHELLE ROETT, MD, MPH, FAAFP, CPE

Georgetown University Medical Center,

Washington, DC

KATE ROWLAND, MD, MS

Rush-Copley Medical Center, Chicago

LINDA SPEER, MD

University of Toledo, $\mathrm{OH}$

DIRECT INQUIRIES TO:

Frontline Medical Communications

7 Century Drive, Suite 302

Parsippany, NJ 07054

Telephone: (973) 206-3434

Fax: (973) 206-9378

EDITORIAL

John Hickner, MD, MSc

Editor-in-Chief

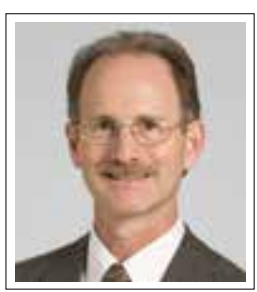

\title{
It's time to change when BP meds are taken
}

I

$\mathrm{n}$ this issue of $J F P$, there is an extraordinarily valuable PURL (Priority Updates from the Research Literature) for you. (See page 362.) PURLs ${ }^{\circledast}$ are written by academic family physicians who comb through volumes of research to identify and then summarize for JFP important studies we believe should change your practice. After reading a PURL, you may find that you have already implemented this new evidence into your practice. In that case, the PURL confirms that you are doing the right thing.

Here is the good news from this month's PURL: Having patients take their blood pressure (BP) medication in the evening, rather than in the morning, leads not only to better BP control but also to a reduction in cardiovascular events. ${ }^{1}$ How

\section{We should all tell our patients to take their BP medication in the evening from now on. What could be an easier way to reduce CV morbidity and mortality?}

large is this effect? This simple intervention nearly cut in half the number of major cardiovascular events-including myocardial infarction, stroke, and congestive heart failure-and the risk for death from a cardiovascular event was reduced $56 \%$. The number needed to treat to prevent 1 major cardiovascular event over the course of 6.3 years was 20 . That means this intervention is more powerful than taking a statin!

The investigators, who call this intervention "chronotherapy" since it takes into account the body's circadian rhythms, have been studying the effect of this simple intervention for many years, and this large randomized trial provides very strong evidence that it's effective. Despite the excellent trial design and execution, some cardiovascular researchers have questioned the integrity of the trial and believe patients should continue to take their antihypertensives in the morning. ${ }^{2}$ The main investigator of the study, however, has provided a very strong rebuttal in print. ${ }^{3}$

I am delighted to see the positive results of this definitive trial of chronotherapy for hypertension. When these investigators published their first randomized trial of chronotherapy in 2010, ${ }^{4}$ which demonstrated a significant BP reduction with evening dosing of antihypertensives, I began telling all of my patients to take at least 1 of their antihypertensive meds in the evening. Maybe I was jumping the gun at that time, but we should all tell our patients to take their BP medication in the evening from now on. What could be an easier way to reduce cardiovascular morbidity and mortality?
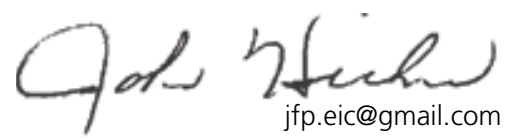

CONTINUED ON PAGE 326 
1. Hermida RC, Crespo JJ, Domínguez-Sardiña M, et al. Bedtime hypertension treatment improves cardiovascular risk reduction: the Hygia Chronotherapy Trial [published online ahead of print October 22, 2019]. Eur Heart J. 2019;ehz754. doi:10.1093/ eurheartj/ehz754

2. Kreutz R, Kjeldsen SE, Burnier M, et al. Blood pressure medication should not be routinely dosed at bedtime. We must disregard the data from the HYGIA project [editorial]. Blood Press. 2020;29:135-136.
3. Crespo JI, Domínguez-Sardiña M, Otero A, et. al. Bedtime hypertension chronotherapy best reduces cardiovascular disease risk as corroborated by the Hygia Chronotherapy Trial. Rebuttal to European Society of Hypertension officials. Chronobiol Int. 2020;37:771-780.

4. Hermida RC, Ayala DE, Mojón A, Fernández JR. Influence of circadian time of hypertension treatment on cardiovascular risk: results of the MAPEC study. Chronobiol Int. 2010;27: 1629-1651. 